1 Tribunal de Justiça do Estado do Rio de Janeiro (TJRJ) - Rio de Janeiro (RJ), Brasil.

adrianalaiafranco@gmail. com

2 Universidade Federal do Rio de Janeiro (UFRJ), Institutos de Estudos em Saúde Coletiva (lesc) - Rio de Janeiro (RJ), Brasil.

\section{Sistema educacional inclusivo constitucional e o atendimento educacional especializado}

\author{
Constitutional inclusive education system and specialized educational \\ care
}

Adriana Marques dos Santos Laia Franco', Gabriel Eduardo Schutz ${ }^{\mathbf{1}}$

DOI: 10.1590/0103-11042019S420

RESUMO Este estudo versa sobre o direito constitucional à educação inclusiva. Com base em pesquisa bibliográfica, por meio de livros, leis, decretos, artigos e convenções internacionais, verificou-se que o ordenamento jurídico constitucional brasileiro adotou o paradigma educacional da inclusão, que prevê a igualdade de condições para o acesso e para a permanência de todos os alunos no ensino regular. A análise da legislação pertinente ao tema mostrou que o sistema educacional inclusivo constitucional, no Brasil, não prevê a existência de ambientes segregados nem de salas especiais. Todos os alunos devem frequentar o ensino regular, sendo ofertado o Atendimento Educacional Especializado, de forma complementar e no turno inverso ao da escolarização, considerando as especificidades dos estudantes com deficiência, de modo a identificar, elaborar e organizar recursos pedagógicos e de acessibilidade que eliminem as barreiras para a plena participação desses alunos.

PALAVRAS-CHAVE Educação. Inclusão educacional. Educação especial. Pessoas com deficiência. Direitos humanos.

\begin{abstract}
This study focuses on the constitutional right to inclusive education. Based on bibliographical research, through books, laws, decrees, articles, and international conventions, we could verify that the Brazilian constitutional legal system adopted the educational paradigm of inclusion, which provides equal conditions for the access and permanence of all students in regular education. The analysis of the applicable law showed that the constitutional inclusive educational system, in Brazil, does not provide for the existence of a segregated environment, nor special rooms. All students must attend regular education and should be offered complementary Specialized Educational Assistance in the inverse shift to that of schooling. This assistance should consider the specifics of the students with disability, in order to identify, elaborate, and organize pedagogical and accessibility resources that eliminate the barriers to the full participation of those students.
\end{abstract}

KEYWORDS Education. Mainstreaming education. Special education. Disabled persons. Human rights. 


\section{Introdução}

O presente artigo tem por escopo apresentar, na perspectiva dos direitos humanos, as principais características do sistema educacional inclusivo estabelecido constitucionalmente no Brasil.

Até o advento da Constituição Federal de 1988, a educação especial no Brasil se caracterizou basicamente por ações isoladas, em que $o$ atendimento se destinava mais às deficiências visuais, auditivas e, em menor escala, às deficiências físicas.

Com a promulgação do novo texto constitucional, mais especificamente em seu art. 208, pode-se estabelecer a premente necessidade da inclusão escolar enquanto preceito constitucional, apregoando o atendimento às pessoas com deficiência na Rede Regular de Ensino, garantido o Atendimento Educacional Especializado (AEE) aos usuários da educação especial.

A Convenção Internacional sobre os Direitos das Pessoas com Deficiência (CDPD) da Organização das Nações Unidas (ONU), também conhecida como Convenção sobre os Direitos das Pessoas com Deficiência, ratificada pelo Brasil em 2009, reconhece a questão da deficiência como um tema de justiça, direitos humanos e promoção da igualdade'.

A promulgação do Estatuto da Pessoa com Deficiência, expressão legal da Convenção Internacional dos Direitos da Pessoa com Deficiência acolhida como emenda constitucional em nosso ordenamento, por meio da promulgação da Lei $\mathrm{n}^{0} 13.146 / 2015$, traz mais elementos para tutela do direito constitucional à educação especial na rede regular de ensino.

Sabe-se que a escola comum se torna inclusiva quando reconhece as diferenças dos alunos diante do processo educativo e busca a participação e o progresso de todos, adotando novas práticas pedagógicas. Não é fácil e imediata a adoção dessas novas práticas, pois ela depende de mudanças que vão além da escola e da sala de aula.

Para que essa escola possa se concretizar, é patente a necessidade de atualização e desenvolvimento de novos conceitos, assim como a redefinição e a aplicação de alternativas e práticas pedagógicas e educacionais compatíveis com a inclusão.

A adoção de um modelo escolar inclusivo exige que o professor rompa com seus posicionamentos sobre o desempenho escolar padronizado e homogêneo dos alunos e desempenhe o seu papel formador, que não mais se restringirá a ensinar somente a uma parcela dos alunos que conseguem atingir o desempenho exemplar esperado pela escola. Assim, ensinará a todos indistintamente.

Da mesma forma, exige-se dos operadores do direito um posicionamento consentâneo com o caráter constitucional da educação inclusiva, atuando na interpretação da lei, não só tutelando o acesso à escola como também a permanência e a participação dos alunos.

Os direitos ao acesso e à permanência os pais já entenderam, e têm sabido buscá-los de forma efetiva. É com felicidade que vemos que as famílias dos alunos em situação de deficiência estão cada vez mais atentas ao regramento de tutela dos direitos relativos à educação especial, na perspectiva da inclusão. No entanto, no que se refere à participação, as famílias nem sempre conseguem identificar o que falta à escola para que os alunos possam ter ganhos relativos à inclusão escolar.

Esses ganhos não podem ser conseguidos a partir de uma diferenciação pela deficiência, que é o que ocorre em muitas situações em que o aluno da educação especial é atendido na sala de aula. Essas situações vão desde a presença de um professor de apoio exclusivo aos currículos e atividades ditas personalizadas, individualizadas, adaptadas unicamente para esse aluno.

Verifica-se uma demanda crescente por parte dos pais dos alunos da educação especial no sentido de as escolas fornecerem o que chamam de 'mediador escolar'.

Esse pleito, além de, em muitos casos, acarretar a contratação desnecessária de profissionais que não possibilitarão ganhos de aprendizado ao aluno, demonstra o desconhecimento desses pais acerca do direito constitucional ao AEE, prestado por professores com formação hábil 
a viabilizar a participação efetiva do aluno na sala de aula comum, com ganhos pedagógicos.

Como se verá - na medida do possível, dados os limites da extensão deste trabalho -, a participação dos alunos da educação especial na escola comum é construída e efetivada por meio do AEE, em horário oposto ao período de aulas do turno regular, devendo o professor do AEE estudar o caso de cada aluno que lhe é encaminhado pela escola - em conjunto com a família e outros profissionais externos que o estejam atendendo -, e avaliar se esse aluno é ou não público-alvo do serviço.

Ao professor do AEE, cabe pesquisar, produzir e propor a aquisição de recursos, ajudas técnicas, tecnologia assistiva e demais apoios que eliminam as barreiras identificadas na comunicação, mobilidade, interação, acesso e permanência dos alunos da educação especial nas escolas comuns. Assim, também, deverá o professor do AEE acompanhar o processo de inserção do seu aluno na sala de aula comum e o uso dos recursos/ tecnologias por ele propostos no plano individual do aluno para eliminação das barreiras à participação desse educando nas atividades com seus pares, na sala de aula comum, no turno regular.

\section{Breve visão histórica}

No final dos anos 1970, o movimento associativo das pessoas com deficiência ganhou visibilidade, de modo que estas tornaram-se ativos agentes políticos na busca por transformação da sociedade. $O$ desejo de serem protagonistas políticos motivou uma mobilização nacional, alimentada pela conjuntura da época. Esse processo se reflete na Constituição Federal promulgada em 1988. A Assembleia Nacional Constituinte (1987-1988), envolvida no espírito dos novos movimentos sociais, foi a mais democrática da história do Brasil, com canais abertos e legítimos de participação popular.

Novos movimentos sociais, entre os quais, o movimento político das pessoas com deficiência, saíram do anonimato e, na esteira da abertura política, uniram esforços, formaram novas organizações, articularam-se nacionalmente e criaram estratégias de luta para reivindicar igualdade de oportunidades e garantias de direitos. Outro fator relevante foi a decisão da ONU de proclamar 1981 como o Ano Internacional das Pessoas com Deficiência (AIPD), fato que colocou as pessoas com deficiência no centro das discussões, no mundo e também no Brasil2.

É importante salientar, com relação a expressão 'pessoa com deficiência', que ela é para destacar que $o$ ato de falar ultrapassa a simples exteriorização de pensamentos ou a descrição de aspectos de dada realidade. As palavras usadas para nomear as pessoas com deficiência comportam uma visão valorativa que traduz as percepções da época em que foram cunhadas.

Para os novos movimentos sociais e suas políticas de identidade, as palavras são instrumentos importantes de luta política. A busca por novas denominações reflete a intenção de rompimento com as premissas de menos-valia que até então embasavam a visão sobre a deficiência. Termos genéricos, como 'inválidos', 'incapazes', 'aleijados' e 'defeituosos', foram amplamente utilizados e difundidos até meados do século XX, indicando a percepção dessas pessoas como um fardo social, inútil e sem valor.

Ao se organizarem como movimento social, as pessoas com deficiência buscaram novas denominações que pudessem romper com essa imagem negativa que as excluía. $\mathrm{O}$ primeiro passo nessa direção foi a expressão 'pessoas deficientes', que o movimento usou quando da sua organização no final da década de 1970 e início da década de 1980, por influência do AIPD. A inclusão do substantivo 'pessoa' era uma forma de evitar a coisificação, contrapondo-se à inferiorização e a desvalorização associadas aos termos pejorativos usados até então.

Posteriormente, foi incorporada a expressão 'pessoas portadoras de deficiência', com o objetivo de identificar a deficiência como um detalhe da pessoa. A expressão foi adotada na Constituição Federal de 1988 e nas Constituições estaduais, bem como em todas as leis e políticas pertinentes ao campo das deficiências. Conselhos, 
coordenadorias e associações passaram a incluir essa expressão em seus documentos oficiais.

Eufemismos foram adotados, tais como: 'pessoas com necessidades especiais' e 'portadores de necessidades especiais'. A crítica do movimento a esses eufemismos se deve ao fato de $o$ adjetivo 'especial' criar uma categoria que não combina com a luta por inclusão e por equiparação de direitos. Para o movimento, com a luta política, não se busca ser 'especial', mas, sim, ser cidadão. A condição de 'portador' passou a ser questionada pelo movimento por transmitir a ideia de a deficiência ser algo que se porta e, portanto, não faz parte da pessoa. Além disso, enfatiza a deficiência em detrimento do ser humano.

Dessa forma, 'pessoa com deficiência' passou a ser então a expressão adotada contemporaneamente para designar esse grupo social. Em oposição à expressão 'pessoa portadora', 'pessoa com deficiência' demonstra que a deficiência faz parte do corpo e, principalmente, humaniza a denominação. Ser 'pessoa com deficiência' é, antes de tudo, ser pessoa humana. É também uma tentativa de diminuir o estigma causado pela deficiência. A expressão foi consagrada pela CDPD, da ONU, em $2006^{2}$.

\section{A Política Nacional de Educação Especial na Perspectiva da Educação Inclusiva}

A Constituição Brasileira de 1988, mais especificamente em seu art. 208 , estabelece a premente necessidade da inclusão escolar enquanto preceito constitucional, apregoando $o$ atendimento às pessoas com deficiência, na Rede Regular de Ensino.

Após 2009 - com a ratificação pelo Brasil da CDPD da ONU, a inclusão do aluno com deficiência no âmbito da escola regular assim como o oferecimento do AEE no contraturno escolar ganharam status de direito constitucional.

Em decorrência desse processo, a antiga concepção de educação especial (substitutiva à escola comum) deu lugar à concepção vigente na atual Política Nacional de Educação Especial na Perspectiva da Educação Inclusiva (PNEEPEI), que completa 10 anos em 2018. Desde seu advento, a educação especial passou a ser uma modalidade transversal a todos os níveis, etapas e modalidades de ensino, ou seja, não mais substitutiva à escola. Seu papel passou a ser, em essência, oferecer recursos, serviços e estratégias de acessibilidade para promover a inclusão escolar.

Nessa perspectiva, o Ministério da Educação/Secretaria de Educação Continuada, Alfabetização, Diversidade e Inclusão editou a PNEEPEI, que acompanha os avanços do conhecimento e das lutas sociais, visando constituir políticas públicas promotoras de uma educação de qualidade para todos os estudantes ${ }^{3}$.

A PNEEPEI de 2008 representa um novo marco teórico e político na educação brasileira. Esse documento define a educação especial como modalidade não substitutiva à escolarização; estabelece o caráter complementar e suplementar do AEE à formação dos estudantes e determina o público-alvo da educação especial, constituído pelos estudantes com deficiência, transtornos globais do desenvolvimento e altas habilidades/superdotação. Na elaboração dessa política, foi seguido o preceito de uma escola em que cada aluno tenha a possibilidade de aprender, a partir de suas aptidões e capacidades. Dessa forma, a educação especial se volta atualmente à tarefa de complementar/suplementar à formação dos alunos que constituem seu público-alvo, por meio do ensino de conteúdos e utilização de recursos que lhes conferem a possibilidade de acesso, permanência e participação nas turmas comuns de ensino regular, com autonomia e independência.

O estudo da publicação 'A consolidação da inclusão escolar no Brasil', de autoria da pesquisadora Martinha Clarete Dutra dos Santos (Diretora de Políticas de Educação Especial do Ministério da Educação no período de 2009 -2016), permite extrair uma rica descrição da PNEEPEI4. 


\section{Objetivo da Política Nacional de Educação Especial na Perspectiva da Educação Inclusiva}

\begin{abstract}
A PNEEPEI tem como objetivo o acesso, a participação e a aprendizagem dos estudantes com deficiência, transtornos globais do desenvolvimento e altas habilidades/superdotação nas escolas comuns, orientando os sistemas de ensino para promover respostas às necessidades educacionais, garantindo:
\end{abstract}

a) Transversalidade da educação especial desde a educação infantil até a educação superior;

b) AEE;

c) Continuidade da escolarização nos níveis mais elevados do ensino;

d) Formação de professores para o AEE e demais profissionais da educação para a inclusão escolar;

e) Participação da família e da comunidade;

f) Acessibilidade urbanística, arquitetônica, nos mobiliários e equipamentos, nos transportes, na comunicação e informação; e

g) Articulação intersetorial na implementação das políticas públicas ${ }^{4}$.

\section{Diretrizes da Política Nacional de Educação Especial na Perspectiva da Educação Inclusiva}

As diretrizes da PNEEPEI se fundamentam na diferenciação para incluir e são extensivas a todas as ações e serviços da educação especial, devendo estar presentes, transversalmente, em todas as modalidades e níveis de ensino ${ }^{5}$.

A educação especial é uma modalidade de ensino que perpassa todos os níveis do sistema educacional, realiza o AEE, disponibiliza os serviços e recursos próprios desse atendimento e orienta os alunos e seus professores quanto a sua utilização nas turmas comuns do ensino regular. O serviço de AEE identifica, elabora e organiza recursos pedagógicos e de acessibilidade que eliminem as barreiras para a plena participação dos alunos, considerando as suas necessidades específicas. As atividades desenvolvidas no AEE diferenciam-se daquelas realizadas na sala de aula comum, e não são substitutivas à escolarização. Esse atendimento complementa e/ou suplementa a formação dos alunos com vistas à autonomia e independência na escola e fora dela.

O AEE deve estar articulado com a proposta pedagógica do ensino comum ao longo de todo processo de escolarização (documento elaborado pelo Grupo de Trabalho nomeado pela Portaria $n^{0} 555 / 2007$, prorrogada pela Portaria $n^{\circ}$ 948/2007, entregue ao Ministro da Educação em 07 de janeiro de 2008) ${ }^{6}$.

Consideram-se serviços e recursos da educação especial aqueles que asseguram condições de acesso ao currículo por meio da promoção da acessibilidade aos materiais didáticos, aos espaços e equipamentos, aos sistemas de comunicação e informação e ao conjunto das atividades escolares.

\section{Salas de Recursos Multifuncionais}

As Salas de Recursos Multifuncionais são espaços localizados nas escolas de educação básica, onde se realiza o AEE. Essas salas são organizadas com mobiliários, materiais didáticos e pedagógicos, recursos de acessibilidade e equipamentos específicos para o atendimento aos alunos público-alvo da educação especial, em turno contrário à escolarização. 
São atendidos, nas Salas de Recursos Multifuncionais, alunos público-alvo da educação especial, conforme estabelecido na PNEEPEI e no Decreto $n^{\circ}$ 6.571/20083.

- Alunos com deficiência: aqueles que têm impedimentos de longo prazo de natureza física, mental, intelectual ou sensorial, os quais, em interação com diversas barreiras, podem obstruir sua participação plena e efetiva na sociedade em igualdade de condições com as demais pessoas ${ }^{6}$.

- Alunos com transtornos globais do desenvolvimento: aqueles que apresentam alterações qualitativas das interações sociais recíprocas e na comunicação, um repertório de interesses e atividades restrito, estereotipado e repetitivo. Incluem-se nesse grupo alunos com autismo, síndromes do espectro do autismo e psicose infantil7.

- Alunos com altas habilidades/superdotação: aqueles que demonstram potencial elevado em qualquer uma das seguintes áreas, isoladas ou combinadas: intelectual, acadêmica, liderança, psicomotricidade e artes, além de apresentar grande criatividade, envolvimento na aprendizagem e realização de tarefas em áreas de seu interesse ${ }^{7}$.

\section{Funções do professor do Atendimento Educacional Especializado}

Os planos de AEE devem ser elaborados individualmente, para cada aluno, e resultam das escolhas do professor quanto aos recursos, equipamentos, apoios mais adequados para que possam eliminar as barreiras que impedem o aluno de ter acesso ao que lhe é ensinado na sua turma da escola comum, garantindo-lhe a participação no processo escolar e na vida social, segundo suas capacidades. Esse atendimento tem funções próprias do ensino especial, as quais não se destinam a substituir o ensino comum nem mesmo a fazer adaptações aos currículos, às avaliações de desempenho e a outros. É importante salientar que o AEE não se confunde com reforço escolar. O professor de AEE acompanha a trajetória acadêmica de seus alunos, no ensino regular, para atuar com autonomia na escola e em outros espaços de sua vida social. Para tanto, é imprescindível uma articulação entre o professor de AEE e os do ensino comum.

Na perspectiva da inclusão escolar, o professor da educação especial não é mais um especialista em uma área específica, suas atividades desenvolvem-se dentro da própria escola (salvo casos em que a escola tiver convênio público para AEE em local externo), cabendo-lhes, no $\mathrm{AEE}$ aos alunos, as seguintes atribuições:

a) identificar, elaborar, produzir e organizar serviços, recursos pedagógicos, de acessibilidade e estratégias, considerando as necessidades específicas dos alunos de forma a construir um plano de atuação para eliminá-las ${ }^{8}$.

b) Reconhecer as necessidades e habilidades do aluno. Ao identificar certas necessidades do aluno, o professor de AEE reconhece também as suas habilidades e, a partir de ambas, traça o seu plano de atendimento. Se ele identifica necessidade de comunicação alternativa para o aluno, indica recursos como a prancha de comunicação, por exemplo; se observa que o aluno movimenta a cabeça, consegue apontar com o dedo, pisca, essas habilidades são consideradas por ele para a seleção e organização de recursos educacionais e de acessibilidade. Com base nesses dados, o professor elaborará o plano de AEE, definindo o tipo de atendimento para o aluno, os materiais que deverão ser produzidos, a frequência do aluno ao atendimento, entre outros elementos constituintes desse plano. Outros dados poderão ser coletados pelo professor em articulação com o professor da sala de aula e demais colegas da escola. 
c) Produzir materiais tais como textos transcritos, materiais didático-pedagógicos adequados, textos ampliados, gravados, como, também, poderá indicar a utilização de softwares e outros recursos tecnológicos disponíveis.

d) Elaborar e executar o plano de AEE, avaliando a funcionalidade e a aplicabilidade dos recursos educacionais e de acessibilidade ${ }^{8}$. Na execução do plano de AEE, o professor terá condições de saber se o recurso de acessibilidade proposto promove participação do aluno nas atividades escolares. O plano, portanto, deverá ser constantemente revisado e atualizado, buscando-se sempre o melhor para o aluno e considerando que cada um deve ser atendido em suas particularidades.

e) Organizar o tipo e o número de atendimentos $^{8}$. O professor seleciona o tipo do atendimento, organizando, quando necessários, materiais e recursos de modo que o aluno possa aprender a utilizá-los segundo suas habilidades e funcionalidades. O número de atendimentos semanais/mensais varia para caso. O professor vai prolongar o tempo ou antecipar o desligamento do aluno do AEE, conforme a evolução do aluno.

f) Acompanhar a funcionalidade e a aplicabilidade dos recursos pedagógicos e de acessibilidade na sala de aula comum do ensino regular, bem como em outros ambientes da escola $^{8}$. O professor do AEE observa a funcionalidade e aplicabilidade dos recursos na sala de aula, as distorções, a pertinência, os limites desses recursos nesse e em outros ambientes escolares, orientando, também, as famílias e os colegas de turma quanto ao uso dos recursos. O professor de sala de aula informa e avalia juntamente com o professor do AEE se os serviços e recursos do Atendimento estão garantindo participação do aluno nas atividades escolares. Com base nessas informações, são reformuladas as ações e estabelecidas novas estratégias e recursos, bem como refeito o plano de AEE para o aluno. g) Ensinar e usar recursos de Tecnologia Assistiva, tais como: as tecnologias da informação e comunicação, a comunicação alternativa e aumentativa, a informática acessível, o soroban, os recursos ópticos e não ópticos, os softwares específicos, os códigos e linguagens, as atividades de orientação e mobilidade ${ }^{8}$.

h) Promover atividades e espaços de participação da família e a interface com os serviços de saúde, assistência social e outros ${ }^{8}$.

Destaque-se ainda que o papel do professor do AEE não deve ser confundido com o papel dos profissionais do atendimento clínico, embora suas atribuições possam ter articulações com profissionais das áreas da medicina, psicologia, fisioterapia, fonoaudiologia e outras afins. O AEE também estabelece interlocuções com os profissionais da arquitetura, engenharia, informática.

No decorrer da elaboração e desenvolvimento dos planos de atendimento para cada aluno, o professor de AEE se apropria de novos conteúdos e recursos que ampliam seu conhecimento para a atuação na Sala de Recursos Multifuncional.

São conteúdos do AEE: Língua Brasileira de Sinais (Libras) e Libras tátil; Alfabeto digital; Tadoma; Língua Portuguesa na modalidade escrita; Sistema Braille; Orientação e mobilidade; Informática acessível; Sorobã (ábaco); Estimulação visual; Comunicação Alternativa e Aumentativa (CAA); Desenvolvimento de processos educativos que favoreçam a atividade cognitiva.

São recursos do AEE: Materiais didáticos e pedagógicos acessíveis (livros, desenhos, mapas, gráficos e jogos táteis, em Libras, em Braille, em caráter ampliado, com contraste visual, imagéticos, digitais, entre outros); Tecnologias de Informação e de Comunicação (Tics) acessíveis (mouses e acionadores, teclados com colmeias, sintetizadores de voz, linha Braille, entre outros); e Recursos ópticos; pranchas de CAA, engrossadores de lápis, ponteira de 
cabeça, plano inclinado, tesouras acessíveis, quadro magnético com letras imantadas, entre outros.

O desenvolvimento dos processos de ensino e de aprendizagem é favorecido pela participação da família dos alunos. Para elaborar e realizar os Planos de AEE, o professor necessita dessa parceria em todos os momentos. Reuniões, visitas e entrevistas fazem parte das etapas pelas quais os professores de AEE estabelecem contatos com as famílias de seus alunos, colhendo informações, repassando outras e estabelecendo laços de cooperação e de compromissos?.

Cabe aqui destacar ainda, como importante função do professor do AEE, a avaliação, em cada caso, da necessidade do aluno em ser acompanhado por um profissional de apoio escolar. Como já foi mencionado, para que a inclusão seja efetiva, são necessários diversos recursos: a parceria entre o AEE e os professores de sala de aula, o amparo das famílias e o investimento em acessibilidade.

Em alguns casos, no entanto, é preciso ainda um elemento a mais: o profissional de apoio escolar. Trata-se de um profissional que acompanha o aluno diariamente, contribuindo para a compreensão de suas características e eliminando barreiras que o impedem de se inserir na vida escolar. Assim, ele complementa o trabalho do educador responsável pela turma, bem como pelo trabalho do professor do AEE.

É muito importante destacar que nem todos que têm Necessidades Educacionais Especiais (NEE) precisam de um auxiliar. Da mesma forma, aqueles alunos que hoje precisam desse acompanhamento, com o passar do tempo, podem ir vencendo antigas barreiras e deixar de precisar desse serviço.

O profissional de apoio escolar - comumente chamado de mediador, quando sua atividade se relaciona com a parte pedagógica - entra em cena quando há algum impedimento à inclusão. Em certos casos, a criança necessita de alguém que a acompanhe em classe, flexibilizando as aulas. Em outros, requer ajuda em questões motoras, com exercícios específicos e adaptações para a escrita. Há ainda alunos que só conseguem frequentar a escola se têm apoio para locomoção, higiene e alimentação, e demandam uma pessoa capacitada para fazer esse atendimento da forma correta, evitando lesões e constrangimentos.

Para cada uma dessas situações, há um profissional que melhor atende às necessidades dos alunos - podendo ser um professor auxiliar, um especialista em inclusão, um estagiário de pedagogia ou psicologia, ou alguém da área de saúde. No entanto, como as escolas podem fazer para lidar com um quadro tão complexo?

O primeiro passo é conhecer bem os alunos com necessidades educacionais especiais, encaminhando-os ao AEE. As características individuais desses alunos serão determinantes para a avaliação de quais e quantos profissionais devem ser contratados.

O passo seguinte é identificar o que a Secretaria de Educação pode oferecer e checar a possibilidade de firmar parcerias com outras instituições, como as de saúde e assistência social, que estão aptas a prestar serviços às escolas. Contratado o profissional de apoio escolar, é preciso incluí-lo na rotina escolar e garantir que ele participe das reuniões pedagógicas. Em contato com o restante da equipe, ele consegue ter um olhar geral sobre o trabalho pedagógico, o que ajuda quando está em sala de aula com o aluno. Ao mesmo tempo, ele compartilha com a equipe informações sobre o desenvolvimento da criança que acompanha. Muitas vezes, é nesse momento que os professores de sala de aula conhecem melhor os estudantes que participam do AEE.

Ademais, a presença do profissional de apoio escolar nas reuniões pedagógicas contribui também para evitar o isolamento dele em relação ao restante do grupo. O ideal é que esse profissional conte com o apoio dos colegas - em especial, do responsável pelo em especial, do responsável pelo AEE - para formular as atividades e encontrar soluções eficientes para que cada aluno seja incluído e aprenda.

Por fim, é preciso ter claras as regras que pautam a relação entre auxiliar e aluno. $\mathrm{O}$ profissional de apoio escolar deve garantir condições para que a criança frequente as aulas 
e aprenda, mas tem de ajudá-la a desenvolver autonomia, estimulando-a a tentar fazer as atividades por si mesmas, sempre que isso se mostrar possível de ser alcançado ${ }^{10}$.

\section{Trabalho conjunto entre o professor do Atendimento Educacional Especializado e o professor da sala de aula comum}

Os professores comuns e os da educação especial precisam se envolver para que seus objetivos específicos de ensino sejam alcançados, compartilhando um trabalho interdisciplinar e colaborativo. As frentes de trabalho de cada professor são distintas: ao professor da sala de aula comum, é atribuído o ensino das áreas do conhecimento, e ao professor do AEE, cabe complementar/suplementar a formação do aluno com conhecimentos e recursos específicos que eliminam as barreiras que impedem ou limitam sua participação com autonomia e independência nas turmas comuns do ensino regular.

As funções do professor de educação especial são abertas à articulação com as atividades desenvolvidas por professores, coordenadores pedagógicos, supervisores e gestores das escolas comuns, tendo em vista o benefício dos alunos e a melhoria da qualidade de ensino, como por exemplo:

- a elaboração conjunta de planos de trabalho durante a construção do projeto pedagógico, em que a educação especial não é um tópico à parte da programação escolar;

- o estudo e a identificação do problema pelo qual um aluno é encaminhado à educação especial;

- a discussão dos planos de AEE com todos os membros da equipe escolar;

- o desenvolvimento em parceria de recursos e materiais didáticos para o atendimento do aluno em sala de aula e o acompanhamento conjunto da utilização dos recursos e do progresso do aluno no processo de aprendizagem;

- a formação continuada dos professores e demais membros da equipe escolar, entremeando tópicos do ensino especial e comum, como condição da melhoria do atendimento aos alunos em geral e do conhecimento mais detalhado de alguns alunos em especial, por meio do questionamento das diferenças e do que pode promover a exclusão escolar 9 .

\section{Período do Atendimento Educacional Especializado}

A Resolução $n^{0}$ 4, de 2 de outubro de $2009^{3}$, deixa claro que o AEE será realizado no turno inverso da escolarização (contraturno), impondo-se às escolas a efetivação de duas matrículas no caso dos alunos com deficiência, transtornos globais do desenvolvimento e altas habilidades/superdotação: uma nas classes comuns do ensino regular e a segunda no AEE.

\section{Considerações finais}

A luta por igualdade e pelos direitos das pessoas com deficiência não é recente e se insere em um processo de reconhecimento e legitimação.

A leitura dos documentos históricos da Assembleia Nacional Constituinte de 1988, em especial, os registros das Atas das reuniões da Subcomissão da Educação, Cultura e Esportes, ocorridas entre os meses de abril e maio 1987, documentam a participação do representante do Fórum Nacional das Pessoas Portadoras de Deficiência e da Secretaria de Assuntos Constituintes da Organização Nacional de Entidades de Deficientes Físicos, professor Paulo Roberto Guimarães Moreira, no movimento constitucional.

Em um de seus momentos de fala, o 
representante do Fórum Nacional das Pessoas Portadoras de Deficiência e da Secretaria de Assuntos Constituintes da Organização Nacional de Entidades de Deficientes Físicos estabelece a agenda política daquele grupo e deixa claro que, no tocante à inserção da educação especial na Constituição Federal de 1988, naquele primeiro momento, desejava-se garantir a educação especial possível para, em momento posterior, com a construção sociocultural que adviria da nova realidade constitucional, avançar no sentido do sistema educacional regular inclusivo, que colocará fim à segregação.

Quase 20 anos depois de promulgada a Constituição de 1988, o Estatuto da Pessoa com Deficiência (Lei n ${ }^{0}$ 13.146/2015), expressão legal da CDPD acolhida como emenda constitucional em nosso ordenamento, desafia uma cultura ainda vigente no País que é a invisibilidade, na medida em que essas pessoas têm seus direitos sistematicamente desrespeitados, inclusive pelo próprio Poder Público, que, em um círculo vicioso de omissão, mantém esse grupo vulnerável à margem da proteção legalmente estabelecida.

Os dez anos de vigência da PNEEPEI foram essenciais para que as famílias, que antes só buscavam as escolas e classes especiais, passassem a matricular seus filhos com deficiência nas escolas comuns. Isso desestabilizou dirigentes e muitos profissionais de instituições especializadas que se recusaram, ao longo dessa década, a abrir mão da escola especial e de outros locais de segregação para a formação (ad aeternum) de pessoas com deficiência.

Paralelamente a isso, as escolas particulares fazem questão sobre o peso do custo da educação inclusiva, especialmente a manutenção do AEE no contraturno. Nesse ponto, merece destaque que 0 art. $9^{\circ} \mathrm{A}$, do Decreto $\mathrm{n}^{\circ}$ 6.253/2007, permite a dupla matrícula dos estudantes da rede pública que recebem AEE, por meio da destinação de recursos do Fundo de Manutenção e Desenvolvimento da Educação Básica e de Valorização dos Profissionais da Educação (Fundeb). Tal subsídio não foi estendido às escolas particulares, que, conforme decidido pelo
Superior Tribunal Federal (STF) no julgamento da ADIN ADI 5357 MC-REF/DF, devem arcar com os custos da educação inclusiva.

Provavelmente seja por força dessas pressões políticas que ainda se tenha tanta dificuldade para que o instituto do AEE receba a devida atenção no âmbito da atividade das escolas regulares, na prática da função fiscalizadora do Ministério da Educação e dos Ministérios Públicos Federais e Estaduais.

Impõe-se aqui uma reflexão acerca do conteúdo político presente na decisão da referida Ação Direta de Inconstitucionalidade (ADI) $\mathrm{n}^{\circ} 5357$, quando explicita que o custeio do AEE não pode ser repassado às mensalidades, anuidades e matrículas.

Assim é que a discussão sobre responsabilidade pelo custo do AEE só se sustenta em um contexto social que não rompeu com a lógica da caridade, na medida em que ainda entende a inclusão como um favor, uma concessão ou uma deferência à pessoa com deficiência.

No entanto, não é este o conteúdo político da decisão do STF. Observe-se que, no mesmo momento em que o STF, intérprete das normas constitucionais, decide sobre quem deve arcar com o custo da inclusão, também deixa clara sua posição política no sentido da interpretação da inclusão como reconstrução do modelo escolar brasileiro.

Nessa toada, a nosso ver, não há sequer que se falar em custo do AEE, mas, sim, em investimento na reconstrução do sistema escolar para $o$ alcance futuro de uma sociedade plural e justa.

A boa notícia é que, conforme Pesquisa Censo do Instituto Nacional de Estudos e Pesquisas Educacionais Anísio Teixeira (Inep), após 10 anos da publicação do Plano Nacional de educação especial, 79,9\% dos alunos em situação de deficiência migraram das instituições de educação para as escolas comuns do ensino regular.

Essa migração tornou e vem tornando esses alunos visíveis, na medida em que traz para a escola regular toda uma geração de estudantes que estaria impedida de se formar com seus pares, dando-lhes possibilidade de ter seu potencial cognitivo mais bem explorado e desenvolvido, e 
aprender por meio de novas formas de ensino e recursos pedagógicos especiais, que possibilitarão sua inclusão pela sociedade e futuramente pelo mercado de trabalho.

Nesse processo de reconstrução do sistema escolar, têm-se, igualmente, ganhos para os alunos fora de situação de deficiência, e seus familiares, pela elucidação das questões desconhecidas, que lhes permitirá ter um olhar esclarecido e não preconceituoso sobre as diferenças, assim como ter um convívio mais amplo e completo na sociedade.

\section{Referências}

1. Brasil. Decreto ${ }^{\circ} 6.949$, de 25 de agosto de 2009 [internet]. Promulga a Convenção In-ternacional sobre os Direitos das Pessoas com Deficiência e seu Protocolo Facultativo, as-sinados em Nova York, em 30 de março de 2007. Diário Oficial da União. 26 Ago 2009. [acesso em 2019 set 10]. Disponível em: http://www. planalto.gov.br/ccivil_03/_ato2007-2010/2009/decreto/d6949.htm.

2. Lanna Júnior MCM. História do movimento político das pessoas com deficiência no Bra-sil. Brasília, DF: Secretaria de Direitos Humanos; Secretaria Nacional de Promoção dos Direitos da Pessoa com Deficiência; 2010.

\section{Colaboradores}

Franco AMSL (0000-0002-4194-2710)* contribuiu substancialmente para a elaboração do rascunho; para a concepção, o planejamento e para a análise dos dados. Schutz GE (00000002-1980-8558)* contribuiu significativamente para a revisão crítica do conteúdo e participou da aprovação da versão final do manuscrito.
3. Brasil. Ministério da Educação. Resolução no 4, de 2 de outubro de 2009. Institui Diretri-zes Operacionais para o Atendimento Educacional Especializado na Educação Básica, modalidade Educação Especial. Diário Oficial da União. 2 Out 2009. [acesso em 2019 set 10]. Disponível em: http://portal.mec.gov. br/dmdocuments/rceb004_09.pdf.

4. Brasil. Ministério da Educação. A consolidação da inclusão escolar no Brasil 2003 a 2016 [internet]. Brasília, DF: MEC; 2016. [acesso em 2019 set 10]. Disponível em: http://www.ufpb.br/cia/contents/ manuais/a-consolidacao-da-inclusao-escolar-no-brasil-2003-a-2016.pdf. 
5. Mantoan MTE. Diferenciar para incluir: a educação especial na perspectiva da educação inclusiva [internet]. Diversa. 2011 set 22. [acesso em: 2019 set 10]. Disponível em: http://diversa.org.br/artigos/diferenciar-para-incluir-a-educacao-especial-na-perspectiva-da-educacao-inclusiva.

6. Organização das Nações Unidas. Convenção sobre os direitos das pessoas com deficiên-cia. Nova York: ONU; 2006.

7. Brasil. Ministério da Educação. Política nacional de educação especial na perspectiva da educação inclusiva [internet]. Brasília, DF: MEC; 2008. [acesso em 2019 set 10]. Dispo-nível em: http://portal.mec.gov. br/arquivos/pdf/politicaeducespecial.pdf.

8. Brasil. Ministério da Educação. Secretaria de Educação Especial. Nota Técnica 19/2010/MEC/SEESP/ GAB [internet]. Brasília, DF: MEC; 2010. [acesso em 2019 fev 20]. Disponível em: https://inclusaoja.com. br/2011/06/03/profissionais-de-apoio-para-alunos- -com-deficiencia-e-tgd-matriculados-nas-escolas-comuns-nota-tecnica-192010-mecseespgab/.

9. Ropoli EA, Mantoan TEM, Santos MTCT, et al. A educação especial na perspectiva da inclusão escolar: a escola comum inclusiva [internet]. Brasília, DF: Ministério da Educa-ção, Secretaria de Educação Especial; Universidade Federal do Ceará; 2010. Coleção A Educação Especial na Perspectiva da Inclusão Escolar. v. 1. [acesso em 2018 dez 13]. Disponível em: http://portal.mec.gov.br/index.php?option=com docman\&view=download\&alias=7103-fasciculo-1-pdf\&Itemid=30192.

10. Camilo C. Inclusão: o espaço dos auxiliares [internet]. Nova Escola. 2013 ago 1. [acesso em 2019 fev 11]. Disponível em: https://novaescola.org.br/conteudo/1692/inclusao-o-espaco-dos-auxiliares.

Recebido em 16/09/2019

Aprovado em 05/11/2019

Conflito de interesses: inexistente

Suporte financeiro: não houve 